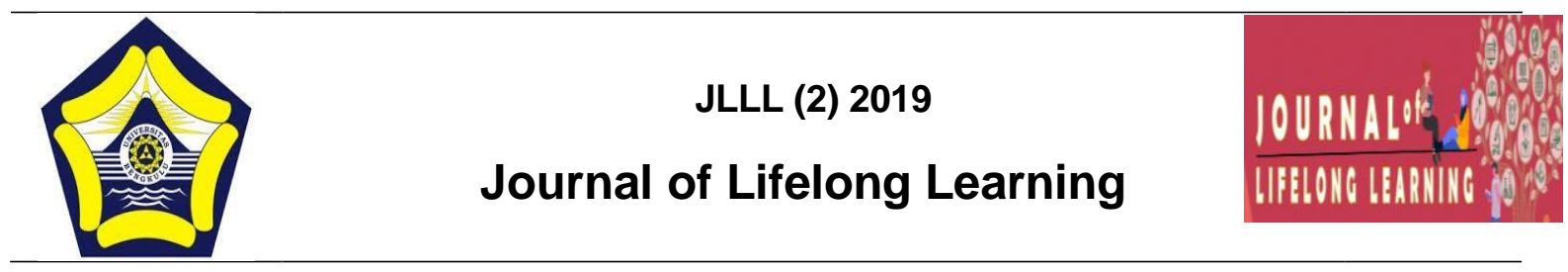

\title{
PENGORGANISASIAN TENAGA DI USAHA KOVENSI \\ ADIGUNA BORDIR KOTA BENGKULU
}

\author{
Novia N Anwari ${ }^{1}$, Wahirriduan ${ }^{2}$, Parlan ${ }^{3}$ \\ ${ }^{1}$ Nonformal Education, University of Bengkulu, Indonesia, Novianurulanawri@gmai.com \\ ${ }^{2}$ Nonformal Education, University of Bengkulu, Indonesia, wahiruddinwadin@gmail.com \\ ${ }^{3}$ Nonformal Education, University of Bengkulu, Indonesia, parlanunib@gmail.com
}

\begin{abstract}
Organizing is a management activity carried out to regulate all the necessary resources intended to be human elements so that the execution and execution of tasks can be completed with success. Humans are the most important element through organizing they can carry out their duties. In this study researchers used qualitative methods with results 1 . Organizing Planned in the Adiguna Embroidery Convection business in the recipients of employees received here are those who want to work hard and discipline with time. 2 . divide up the work of Mr. Suyono to distribute the work to employees even though the results obtained every day employees with each other are different but the work is done well. 3. Classify Activities into Practical Units with the provision of modern means of making the work practical so that the work done is more efficient and effective can be done well, on time and the results are neater. 4. Determining the obligations that must be performed by the employee to provide adequate means of equipment and physical space that the employee needs to do is work according to the field of work position. the room and facilities as a means of supporting the production process are adequate and the material provided by Mr. Suyono is commensurate with the amount done even more 5 . The assignment of personnel who are capable of working on the production process of clothing is good even though there is no special training for employees in Adiguna Embroidery Convection business 6 . Delegation of authority within the Adiguna Convection Embroidery organizational structure in the form of a line based on orders and supervision in one hand.
\end{abstract}

Keywords: organizing, labor

(c) 2019 Dept of Nonformal Education UNIB

Address correspondence:

e-ISSN

JI. W.R. Supratman, Kandang Limun, Muara Bangka Hulu,

Kota Bengkulu, Bengkulu 38371 


\section{PENDAHULUAN}

Bisnis Konveksi adalah salah satu jenis bisnis yang cukup populer di Indonesia. Kepopuleran bisnis Konveksi utamanya adalah disebabkan karena dua hal. Pertama, karena produk yang dihasilkan oleh industri Konveksi, yaitu pakaian merupakan salah satu kebutuhan dasar manusia, maka market untuk bisnis Konveksi akan selalu ada. Pangsa pasar yang jelas, membuat tidak sedikit orang yang berusaha memaksimalkan potensi dari bisnis Konveksi. Yang kedua, bisnis Konveksi menjadi populer karena entry barrier untuk bisa memulai bisnis ini tidak terlalu besar. Seseorang bisa memulai sebuah bisnis Konveksi dengan hanya bermodalkan dua atau tiga buah mesin jahit dan mesin jahit adalah salah satu mesin produksi termurah. Tidak seperti mesin-mesin produksi di industri lainnya yang harganya bisa mencapai ratusan juta atau bahkan milyaran rupiah, seseorang bisa memulai berbisnis Konveksi dari garasi rumahnya yang luasnya hanya beberapa meter persegi saja, tidak perlu membuat pabrik yang luasnya ratusan atau ribuan meter persegi. Karena entry barrier yang tidak terlalu besar inilah tidak sedikit orang yang berani mencoba berbisnis Konveksi.

Pengorganisasian merupakan kegiatan manajemen dilaksanakan untuk mengatur seluruh sumber-sumber yang dibutuhkan termaksud unsur manusia sehingga pelaksanaan dan pengerjaan tugas dapat diselesaikan dengan sukses. Manusia merupakan unsur yang paling penting melalui pengeorganisasian mereka dapat melakasanakan tugas-tugasnya pengorganisasian merupakan salah satu bagian terpenting dalam manajemen kewirausahaan apalagi dalam usaha di Konveksi Adiguna Bordir ini sudah memiliki 38 karyawan . Karena dengan pengorganisasian berarti akan memadukan seluruh sumber-sumber yang ada dalam organisasi, baik yang berupa sumber daya manusia maupun sumber daya lainnya ke arah tercapainnya suatu tujuan.

Dari sini peneliti ingin mengetahui bagaimana cara pengelolah di konveksi Adiguna untuk melakukan pengorganisasian tugas, tanggung jawab, dan wewenang karyawan terhadap tugasnya agar tujuan dan target pencapaian dalam suatu produksi terhadap jumlah permintaan jasa terlaksanakan dengan baik dan tepat waktu serta sesuai dengan hasil yang inggin dicapai.

\section{METODE}

Dalam penelitian ini diarahkan pada upaya menemukan teori-teori yang bersifat kualitatif deskriftif karena permasalahan yang ada dalam penelitian ini tidak berkenaan dengan angkaangka, tetapi menguraikan,menggambarkan dan menelaah suatu kasus secara lebih rinci dan detail tentang pengorganisasian tenga kerja pada lembaga usaha Konveksi Adiguna bordir. Dalam penelitan ni, digunakan kualitatif deskriftif. sebagai instrument utama dalam penelitian kualitatif, peneliti berpartisipasi secara tidak langsung hanya menganalisa, mewawancarai, mengobservasi,langkahnya yaitum menganalisa data yang ada.

\section{HASIL DAN PEMBAHASAN}

Pengorganisasian yang direncanakan untuk menerima karyawan yang bekerja pada lembaga usaha Konveksi Adiguna Bordir ini ialah orang yang mau disiplin dan bekerja keras. Untuk alat sarana dan prasarana serta bahan-bahan yang digunakan sebagai proses produksi sudah baik kerena alat sarana dan bahan yang digunakan dalam memproduksi pakaian lebih 
banyak daripada jumlah yang dikerjakan.Pakaian yang diproduksi setiap harinya dikerjakan sesuai dengan pesanan dari konsumen.

Bapak suyono melakukan pembagi habis pekerjaan kepada karyawannya walaupun hasil produksi karyawan dengan karyawan berbeda setiap harinya tetapi pekerjaan dapat terselasikan dengan baik dan tepat waktu. Karyawan yang bekerja di Konveksi Adiguna Bordir sudah mengetahui tugas dan tanggung jawabnya tetapi masih di bawah naungan dan arahan pimpinan agar hasil yang diperoleh sesuai dengan pesanan konsumen, kerena sudah dibagikan ke tempat pembagian pekerjaan sesuai dengan bidang keahlian dan kemampuan karyawan masingmasing.Pengolongan kegiatan pekerjaan dalam satuan yang praktis Bapak Suyono Adiguna selaku pimpinan pengelolah usaha Konveksi Adiguna Bordir menepati karyawan sesuai keahlian dan kemampuannya masing sehingga pekerjaan yang dkerjakan dapat dikuasai dan menghasilkan suatu hasil produksi yang baik pula baik waktu pekerjaan dan kualitas hasil produksi yang dikerjakan.Kewajiban dalam menentukan ruangan dan alat sarana dan prasarna.Alat - alat sarana di Konveksi Adiguna Bordir sudah memadai didalam proses produksi pakaian apalagi dengan menggunakan alat- alat yang sudah canggih dan berbasis komputer membuat pekerjaan menjadi efektif dan efesiensi.

Penugasan personil yang cakap. karyawan - karyawan yang bekerja di lembaga usaha Konveksi Adiguna Bordir telah bekerja dengan baik menghasilkan suatu hasil produksi yang baik dan mutu yang berkualitas serta hasilnya sesuai dngan hasil dan target yang telah direncanakan sebelumnya.Pedelegasian wewenang struktur organisasi usaha Konveksi Adiguna Bordir berbentuk organisasi garis (line organization). Alasannya adalah didasarkan pada perintah dan pengawasan berada dalam satu tangan. Hubungan kerja langsung dari pimpinan kepada bawahannya. Struktur organisasi dari Konveksi Adiguna Bordir dibentuk untuk menentukan posisi wewenang, tugas, tanggung jawab dan hubungan antar karyawan di dalam perusahaan.

\section{PENUTUP}

\section{KESIMPULAN}

Dari hasil lapangan tentang pengeorganisasian tenaga kerja pada lembaga usaha Konveksi Adiguna Bordir berdasarkan masalah, tujuan penelitian, hasil penelitian dan pembahasan maka dapat disimpulkan bahwa:

1. Pertama : Dalam pengorganisasian yang di rencanakan di usaha konveksi Adiguna Bordir ini bahwa ada perencanaan pengorganisasian yaitu ketentuan dan persyaratan khusus untuk bekerja disini ialah disiplin dan bekerja keras. Untuk alat sarana dan prasarana serta bahanbahan yang digunakan sebagai proses produksi sudah baik kerena alat sarana dan bahan yang digunakan dalam memproduksi pakaian lebih banyak dari pada jumlah yang dikerjakan

2. Kedua : Dalam membagi habis pekejaan di Konveksi Adiguna Bordir ada proses pembagian pekerjaan karyawan sesuai dengan bidang keahliannya masing-masing. Bapak Suyono 
selaku pimpinan pengelolah Konveski Adiguna Bordir melakukan pembagian habis pekerjaan kepada karyawan walaupun hasil pekerjan setiap karyawan satu dan karyawan lainnya berbeda setiap harinya, tetapi pekerjaan selesai tepat waktu dan pekerjaan dapat diselesaikan dengan baik sesuai dengan target yang di tentukan sebelumnya. untuk mengetahui keahlian karyawan bapak Suyono Adiguna melakukan training 1 minggu untuk melihat hasil kerjanya dan kedisiplin karyawan baru. Setiap pekerjaan yang di lakukan dalam proses produksi karyawan sudah mengetahui tugas dan tanggung jawabnya tetapi masih di bawah arahan pimpinan agar hasil yang diperoleh sesuai dengan pesanan konsumen.

3. Ketiga : Penggolongan pekerjaan yang praktis sesuai dengan bidang keahlian karyawan di usaha Konvesksi Adiguna Bordir ada pengolongan pekerjan yang praktis dengan disediakannya alat- alat sarana yang berupa mesin yang pekerjaannya sudah menggunakan alat lisrik, alat bordir sudah berbasis komputer sedangkan penyablon masih menggunakan alat tradisional dan Bapak Suyono Adiguna selaku pimpinan pengelolah usaha Konveksi Adiguna Bordir menepatkan karyawan sesuai keahlian dan kemampuannya masing sehingga pekerjaan yang dikerjakan dapat dikuasai dan menghasilkan suatu hasil produksi yang baik pula baik waktu pekerjaan dan kualitas hasil produksi yang dikerjakan.

4. Keempat kewajiban yang harus dilakukan karyawan ialah bekerja sesuai dengan bidang tempat pembagian posisi pekerjaannya. Dimana di Usaha Konveksi Adiguna sudah ada tempat pembagian posisi pekerjaan karyawan dengan tujuan agar karyawan dapat bekerja sesuai dengan tugas dan tanggung jawabnya masin-masing. Alat - alat sarana di Konveksi Adiguna Bordir sudah memadai didalam proses produksi pakaian apalagi dengan menggunakan alat- alat yang sudah canggih dan berbasis komputer membuat pekerjaan menjadi efektif dan efesiensi.

5. Kelima Penugasan personil yang cakap terhadap karyawan. Karyawan mempunyai hubungan yang harmonis baik sesama karyawan maupun dengan atasan. Karyawan mau di ajak kerjasama dengan baik, mengikuti aturan datang dan pulang tepat waktu serta mau di berikan arahan yang baik oleh atasan dan mau menerima saran serta melaksanakannya. Karyawan yang bekerja di lembaga usaha Konveksi Adiguna Bordir telah bekerja dengan baik menghasilkan suatu hasil produksi yang baik dan mutu yang berkualitas serta hasilnya sesuai dengan hasil dan target yang telah direncanakan sebelumnya. Reward yang diberikan bapak suyuno tidak ada hanya saja berupa THR setiap tahunnya yang diberikan kepada karyawan..

6. Keenam di usaha konveksi Adiguna Bordir memiliki berbentuk struktur organisasi garis / line organizing. Alasanya adalah didasarkan pada perintah dan pengawasan berada dalam satu tangan

\section{REFERENSI}

Arikunto,Suharismi.1998. Metode Peneitian Kualitatif Dan Kuantitatif.Jakarta: PT Rinerka Cipta. Budiono.2005 Kamus Besar Bahasa Indonesia,Karya Agung:Surabaya 
Danim sudarwan. 2002. Inovasi pendidikan : dalam upaya peningkatan profosinalisme tenaga pendidik. Cetakan pertama. Bandung: Cv putsaka setia

Direktorat Jenderal Pendidikan Luar Sekolah dan Pemuda. 2004. Pedoman Penyelenggaraan

Program Kecakapan Hidup (lif Skill) Pendidikan Nonformal. Jakarta: Departemen

Pendidikan Nasional.

Direktorat Pendidikan Kesetaraan Direktorat Jenderala Pendidian Nonformal dan Informal. 2007. Acuan Standar Kompetensi dan Kompetensi Dasar Pendidikan Kesetaraan Keterampulan Fungsional Program paket $B$ dan Paket $C$ Keterampilan Bermatapencaharian (Perikanan). Jakarta: Departemen Pendidikan Nasional

Depdiknas.2003.Undang-Undang No 20 Tahun 2003 Tentang Sistem Pendidikan Nasional,Jakarta :Dirjen Didasdem.

Hasibuan , Melayu S.P..1996, Organisasi Dan Motivasi, Bumi Aksara, Jakarta http://www.pengertianpengertian.com/2011/10/pengertiandokumentasi. Instruksi Presiden (Inpres) Nomor 4 tahun 1995 tanggal 30 Juni 1995 tentang Gerakan Nasional Memasyarakatkan dan Membudayakan Kewirausahaan

Lext J .Moleong.1995. Metode Penelitian Kualitatif.Bandung :PT.Remajarosdakarya.Bandung Nasution. (2003). Meteologi Penelitian Kualitatif Bandung:Rosda

Meleoong L.J (2007) metode penelitian kualitatif. Bandung :Rosda

Prinst,Darwan,Hukum Ketenagakerjaan Indonesia,Bandung PT Citra Aditya Bakti 2000

Ramli ,Rusli Dan Adi Warsidi, 2001. Asas-Asas Manajemen, Modul 4,Jakarta: Pusat.Penerbit.Universitas Terbuka

Robbins Stephen, 1994," Prilaku Orgnisasi", Prentice Hall, Edisi Sepulluh Sabardini , 1994, “ Peningkatan Kinerja Melalui Prilaku Kerja Berdasarkan Kecerdasan Emosional', Telaah Bisnis, Vol 1, No 1

Silalahi, Ulbert, 2011, Studi Tentang Ilmu Administrasi, Teori Dan Dimensi, CV Sinar Baru, Bandung

Siagian P.S. 1991. Manajemen Sumber Daya Manusia. Bumi Aksara:Jakarta

Siagian P.S . 1995 teori pengembangan organisasi. Bumi Aksara:Jakarta

Sugiyono .2010.Metode Penelitian Kuantitatif Kualitatif Dan R \& D. Bandung :Alfabet

Sudjana, Nana. 2010 Manajemen Program Pendidikan Untuk Pendidikan Non Formal Dan Pengembangan Sumber Daya Manusia. Bandung: Falah Production

Terry, George R, 1996, Dasar-Dasar Manajemen, Bumi Aksara, Jakarta

Undang - Undang No 23 Tahun 2003 Tentang Sistem Pendidikan Nasional

Yusuf, Nasrullah. (2006), Wirausaha Dan Usaha Kecil, Jakarta; Modul PTKPNF Depdiknas.

Zimmer, Thomas W Dan Scarborough, Norman M 2008. Kewirausahaan Dan Manajemen Usaha Kecil, Jakarta:Selemba Empat 